Article

\title{
Sustainability in the Opera Sector: Main Drivers and Limitations to Improve the Environmental Performance of Scenography
}

\author{
Mercè Roca ${ }^{1,2,3, * \mathbb{C}}$, Jaume Albertí ${ }^{1}$, Alba Bala ${ }^{1}$, Laura Batlle-Bayer ${ }^{1}$, Joan Ribas-Tur ${ }^{1,2}$ \\ and Pere Fullana-i-Palmer ${ }^{1}$ (i) \\ 1 UNESCO Chair in Life Cycle and Climate Change ESCI-UPF, Universitat Pompeu Fabra, Passeig Pujades 1, \\ 08003 Barcelona, Spain; jaume.alberti@esci.upf.edu (J.A.); alba.bala@esci.upf.edu (A.B.); \\ laura.batlle@esci.upf.edu (L.B.-B.); joan.ribas@esci.upf.edu (J.R.-T.); pere.fullana@esci.upf.edu (P.F.-i.-P.) \\ 2 ESCI-UPF Research in International Studies and Economics (RISE), Universitat Pompeu Fabra, \\ Passeig Pujades 1, 08003 Barcelona, Spain \\ 3 UPF Barcelona School of Management, Carrer de Balmes, 132-134, 08008 Barcelona, Spain \\ * Correspondence: merce.roca@esci.upf.edu; Tel.: +34-93-295-4710
}

check for

updates

Citation: Roca, M.; Albertí, J.;

Bala, A.; Batlle-Bayer, L.; Ribas-Tur, J.;

Fullana-i-Palmer, P. Sustainability in

the Opera Sector: Main Drivers and

Limitations to Improve the

Environmental Performance of

Scenography. Sustainability 2021, 13,

12896. https://doi.org/10.3390/

su132212896

Academic Editor: Ermanno C. Tortia

Received: 29 October 2021

Accepted: 19 November 2021

Published: 22 November 2021

Publisher's Note: MDPI stays neutral with regard to jurisdictional claims in published maps and institutional affiliations.

Copyright: (c) 2021 by the authors. Licensee MDPI, Basel, Switzerland. This article is an open access article distributed under the terms and conditions of the Creative Commons Attribution (CC BY) license (https:/ / creativecommons.org/licenses/by/ $4.0 /)$.

\begin{abstract}
Private and public organizations are becoming increasingly involved in achieving the Sustainable Development Goals. This includes organizations within the cultural sector, with a central role in the progress of society. This study presents a state-of-the-art analysis of actions towards sustainability of the opera sector with a life cycle perspective and focusing on the impact of opera sets' scenery. Our research is based on a review of literature and experiences, the results of interviews, a survey, and an experts' forum to analyze the related systems, standards, and practices. The study contributes with novel research that provides an understanding of the factors that determine the environmental performance which are synthesized with a sustainability SWOT analysis. Findings are relevant for academic researchers analyzing the potential conflicts among organizational strategic goals and sustainability and for scenic arts' practitioners and managers who aim to develop a roadmap towards improving the sustainability of their sector.
\end{abstract}

Keywords: cultural sector; opera; sustainability roadmap; life cycle thinking; sustainability SWOT analysis

\section{Introduction}

The environmental threats linked to human activities are a high priority in the global agenda. At a worldwide scale, the United Nations (UN) released the Sustainable Development Goals (SDGs) in 2015 [1] which aimed to generate a common taxonomy and guideline to achieve peace and prosperity for people and the planet. The European Union (EU) has been leading increasingly ambitious goals at the Conferences of the Parties (COP), pushing for a bigger commitment to carbon neutrality [2]. Moreover, the European Commission (EC) fostered the development of the EU Green Deal, which sets environmental threats as a core priority of public policies [3]. The EC also contributes to developing a roadmap towards a more environmentally sustainable society through its Circular Action Plan [4].

Private and public organizations are becoming increasingly involved in the achievement of the SDGs. From a climate action perspective, organizations are pledging around the climate emergency by adopting guidelines and standards, such as those from the World Business Council on Sustainable Development (WBCSD), to assess their environmental impacts. Likewise, a group of international NGOs have joined efforts to launch the ScienceBased Initiative (SBTi) providing companies with a path to reduce emissions in line with the Paris Agreement (PA); however, achieving the shift to sustainable development is beyond the reach of any single organization as a common vision from industries and sectors is needed to enact such an ambitious transformation [5]. Fostering action and collaboration 
to reach agreed sectoral goals is, therefore, a necessary endeavor of sustainable development. These agreed goals should be the basis for a detailed roadmap to be followed by all organizations within a particular sector.

The World Summit of the United Cities and Local Governments (UCLG) of 2010, approved the Policy Statement "Culture is the Fourth Pillar of Sustainable Development advocating to promote culture as specific dimension of sustainable development, fully interconnected with, and as important as, the other three, economic growth, social inclusion and environmental balance [6]. The year 2021 has been declared the International Year of Creative Economy for Sustainable Development to be led by the UN Conference on Trade and Development (UNCTAD), in consultation with UNESCO and other relevant UN entities. This means to recognize the role of cultural values and creative expressions in supporting the SDG. Within the cultural sector, initiatives have emerged to go beyond the incorporation of notions of sustainability in content dissemination by promoting the evaluation and development of mechanisms to mitigate the impact that the industry itself generates. In the domain of museums, for example, the concept of sustainable culture [7] and the analysis of the environmental impacts of the sector $[8,9]$ are on the rise. Seemingly, several sectors within the creative and scenic arts are working towards the incorporation of sustainability-related criteria in their activities, such as the notion of green shooting in the audio-visual sector [10], and the evaluation of the sustainability of music concerts and festivals [11]. In this context, the Opera sector, as a relevant flagship industry within the performing arts, has recently and notoriously initiated actions towards the adoption and dissemination of more sustainable practices by evaluating and mitigating its own impacts and engaging in a sectoral roadmap towards the achievement of environmental goals [12].

This study presents work aiming to contribute to the analysis of the required actions that the opera sector needs to foster eco-design and resource efficiency, mitigating its environmental impacts, with a particular focus on the activities associated with the management of opera sceneries. This work aims to identify the main strengths, weaknesses, challenges, and opportunities surrounding the environmental impacts associated with the life cycle (LC) of opera sets and their potential role in catalyzing a general sectoral roadmap.

Despite some individual organizations within the opera sector having promoted initiatives to improve their sustainability, little effort has been made to pursue common standards to enhance sectoral sustainability [13]. The most salient impacts of the sector are related to the energy used in running the theatre infrastructures, mainly lighting and HVAC (heating, ventilation, air conditioning), which have focused attempts to enhance their sustainability [13]. Contrarily, opera sceneries have received little attention; however, scenery production and management are common activities to all opera organizations which involve cycles of assembly, disassembly, storing, transporting, and final disposal, which entail a large usage of resources and energy along their LC. Several inherent characteristics of opera sets may justify the lack of attention placed so far on their environmental impacts. First, opera sets are constitutive of artistic creations. As such, any intention to enhance their environmental sustainability not only requires economic and organizational resources but also needs to be confronted with artistic criteria linked to craftsmanship tradition and aesthetic parameters that hinder standardization [14]. On the other hand, the fact that they are temporary in nature may from the outset have caused them to appear both more difficult and less pressing to act upon [15]; however, sceneries might in fact be used during extended periods of time and their LCs are likely to imply abundant consumption of energy and materials and to generate waste needing to be managed.

This study is based on a state-of-the-art review; the realization of six in-depth expert interviews; the realization of a survey to opera technicians; and the insights of a forum of opera professionals. The study, which is the first published state of current environmental considerations in opera sets' production, systematizes knowledge around the environmental footprint of opera sets using a LC thinking approach to identify the critical factors to be considered in eco-design and eco-innovation [16]. The paper aims to contribute to the development of a sectoral roadmap which in turn establishes a benchmark for other scenery 
arts, ultimately contributing to the achievement of the SDGs in the arts and cultural sector. A related goal of the study is to raise awareness, not only amongst the artistic, technical and production departments directly involved with the LC of opera sets, but also amongst the management of sector entities and public authorities, that take decisions that affect the integration of environmental practices in cultural venues and organizations.

The paper is structured as follows: the next section presents the methodology of our study, the research process and sources of information used, namely, a literature review, in-depth interviews to opera professionals, a survey, and an experts' forum. The results section analyses the information obtained from these sources. The discussion section is presented in the form of a SWOT analysis synthesizing the main factors determining the environmental impacts of the sector and, particularly, those linked with the LC of opera sets, which are derived from our results and linked with previous studies. The conclusions section stresses the contribution of our research, its limitations, and further extensions.

\section{Methodology}

The study is grounded on the review of previous experiences and based on data gathered from interviews, a survey, and the results of an ulterior experts' forum aimed at identifying the main drivers and limitations to foster the introduction of more sustainable practices in opera sets' production. Given the scarcity of literature analyzing the sectoral determinants of sustainability, the sequential phases of our research, using qualitative (interviews) as well as quantitative (survey) information gathering techniques allowed a thorough identification of the factors and quantifying of their relevance. The final experts discussion forum was used to validate the results. The SWOT analysis presented in the discussion section, synthesized the findings of our research.

This section provides details of the methodology used in each of the phases of our research and their link with the objectives pursued. Figure 1 depicts the research process stages, which correspond with the different sources of information used.

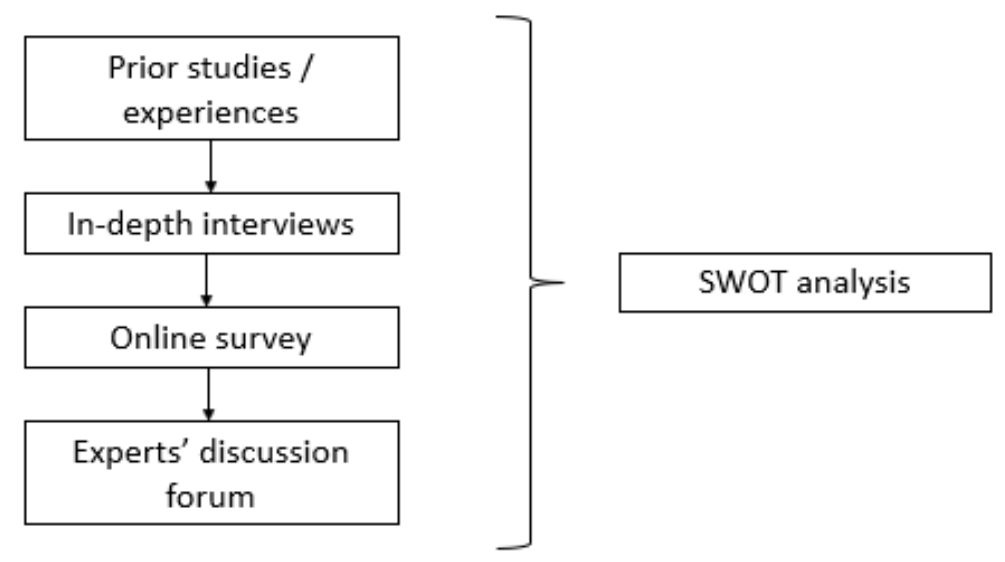

Figure 1. Phases of the research process.

\subsection{Prior Studies/Experiences}

Literature analyzing the sustainability of the opera sector is scarce. Our review of prior studies and experiences has covered the existing peer-reviewed academic literature relating to the sustainability of the scenery arts sector, as well as Masters' and PhD theses linked with the topic. We have complemented this literature review with a review of sustainability reports and public information published by pioneering opera organizations, with the aim to identify the activities related to opera sceneries that have a relevant environmental impact and the challenges that these may pose to enhancing the sustainability of the opera sector. 


\subsection{In-Depth Interviews}

Based on the prior initiatives, we designed a protocol to conduct in-depth structured interviews to a panel of 6 opera sceneries experts. The interviewees were professionals working in the technical departments of 4 different European opera houses from 3 different countries (Belgium, Finland, and France). Table 1 provides details of the participants.

Table 1. Country, organization, and positions held by the in-depth interview participants.

\begin{tabular}{ccc}
\hline Country & Organization & Position \\
\hline Belgium & La Monnaie & $\begin{array}{c}\text { Head of set workshops and design office } \\
\text { Environmental policy manager }\end{array}$ \\
Finland & Finish National Opera and Ballet & Head of set workshop \\
France & Lyon Opera house & Painting manager \\
France & Theatre du Chatelet (Paris) & Head of the design office in the workshops \\
\end{tabular}

The interview protocol was divided into 3 sections. In the first section interviewees were asked to identify the different environmentally relevant flows within the life cycle stages of opera sets. The second section of the interview requested for detailed information on each of the stages of the life cycle of opera sets (raw material sourcing, set production, use, end-of-life treatment, recycling, and final disposal, and the impact of these activities in terms of the energy used, the materials consumed, and the disposal of waste). The third and last section gathered insights regarding the existing sustainability practices, particularly with respect to opera sets, their prospective development, and the challenges these posed to the sector. The detailed protocol of the interviews is included as Supplementary material (S1).

\subsection{Survey}

The insights gained with the interviews were used to design a survey that was sent to the Technical and Production Forum of Opera Europa, including 143 opera organizations and received 24 responses (16.8\% response rate).

The sample of participants includes a representation of 24 Opera Houses from $13 \mathrm{Eu}-$ ropean countries. According to the responses obtained, the represented organizations build an average of 12.73 sets yearly, of which $58.7 \%$ are built in their own workshops. The respondents hold positions as deputy directors/managers (12), technical managers/directors (14), production managers (5) or head of set workshops (9) in their corresponding organization. The respondents indicated to have a minimum of 2 to 38 years of experience in the performing arts sector (average $=20.96$, Std.Dev. $=9.029$ ).

The survey was aimed at analyzing aspects related with the organizational environmental practices with respect to opera sets, the existence of impact assessment and environmental management systems, and the barriers and challenges to improve the sustainability of opera sets in the opera sector. The full questionnaire of the survey is included as Supplementary material (S2).

\subsection{Experts' Discussion Forum}

The preliminary results of the survey were presented at the forum of Opera sector professionals of Opera Europa. The forum gathered a total of 48 professionals at the technical departments of 24 opera organizations of 19 European countries.

The insights gained in the interviews and the survey were briefly presented, making it explicit that the forum aimed to contrast these with the views of the attendants. Participants were asked to identify the activities generating the main environmental impacts in the sector and in the specific activities related with opera sets, as well as to discuss the main challenges and barriers encountered in the pursuit of a roadmap towards sustainable practices in the opera sector. The meeting took place via an online platform where participants could both leave their insights in written form, as well as openly participate aloud with video-camera 
interaction. This enabled a fluid participation in the discussion, which lasted for an hour and $40 \mathrm{~min}$.

The insights gained from the chat contributions and the oral discussion were later transcribed. We engaged in qualitative content analysis [17] of the issues discussed by classifying the relevant pieces of information collected into pre-specified categories associated with the scope and topic of the insight. In particular, we classified the insights depending on whether they corresponded with an organizational level, a sectoral level or external factors to the opera sector such as political, economic, social, technological or legal forces affecting sustainability related initiatives. Organizational insights were in turn classified depending on whether they related with the resources required to put sustainability initiatives into practice, the existing knowledge to realize them, the alignment of criteria, priorities and interests guiding their materialization, and finally, the existence of managerial and organizational commitment to succeed in doing so. Table 2 illustrates the categories established to classify insights.

Table 2. Categories for the classification of the forum insights.

\begin{tabular}{|c|c|c|}
\hline Domain & Category & Description \\
\hline \multirow{4}{*}{ Organization } & Resources & $\begin{array}{l}\text { Need/existence of additional resources (e.g., work time, } \\
\text { storage space, and money) to put initiatives into practice. }\end{array}$ \\
\hline & Knowledge & $\begin{array}{l}\text { Need/existence of capacitation, awareness, and } \\
\text { substantiating data to put initiatives into practice. }\end{array}$ \\
\hline & Criteria & $\begin{array}{c}\text { Existence/alignment of (competing) criteria, priorities, } \\
\text { and stakeholders' interests/values facilitating/hindering } \\
\text { putting initiatives into practice. }\end{array}$ \\
\hline & Management & $\begin{array}{l}\text { Need/existence of managerial/organizational } \\
\text { commitment to set goals and put initiatives into practice. }\end{array}$ \\
\hline \multicolumn{2}{|c|}{ Sector } & $\begin{array}{l}\text { Need/existence of changes and leadership at a sectoral } \\
\text { level that enhance/hinder initiatives. }\end{array}$ \\
\hline \multicolumn{2}{|c|}{ External } & $\begin{array}{c}\text { Need/existence of external political, economic, social, } \\
\text { technological, and legal forces to put initiatives } \\
\text { into practice. }\end{array}$ \\
\hline
\end{tabular}

The classification of the 42 pieces of insights collected was cross validated by two researchers in our team, who were asked to independently classify them, reaching an initial $81.0 \%$ coincidence. The 8 pieces of information that the two researchers sorted differently are considered in the analysis of both categories in which they classified them.

\section{Results}

\subsection{Previous Experiences and Studies}

Prior to the outbreak of COVID-19, the 15,000 performances and nearly 2000 productions yearly, contributing to the creation of around 50,000 permanent jobs, selling 25 million tickets, and generating a turnover of EUR 5000 million yearly [18]. Some theatres and opera houses have for some years moved towards adopting sustainability practices $[19,20]$ and others are nowadays initiating sectoral collaborative programs to analyze further actions to be taken [15,21]; however, the scarcity of resources and existence of competing priorities have hindered their wider diffusion [22]. According to Opera Europa [15], together with its digitalization and the promotion of equality, there are three main areas that are to be tackled with urgency by the sector which have a direct relation to its environmental impacts: (1) impacts related with the footprint of theatre facilities, including energy consumption and its sourcing; (2) those linked with the footprint of sets and the materials used on stage; and (3) the indirect effects of opera activity, such as audience and staff mobility. In parallel, Opera for Peace, a cultural and awareness raising international initiative, which gathers more than 120 partners of opera related organizations (opera houses, festivals, and other institutions), has recently established a collaboration agreement with the Organization for Climate and Circular Economy (OCCE) to perform events related to the circular economy 
paradigm and the environment. Its objective is to activate creative collaborations to form a think-tank for the promotion of communication and educational initiatives addressed to opera artists, around the concept of Circular Culture [21].

Besides these unique sectoral initiatives, some individual opera organizations have for some years been undertaking actions towards sustainability. Most of them have focused their efforts on mitigating the environmental impacts associated with the opera theatre infrastructures - mostly lightning, HVAC, and energy sourcing. Some pioneering initiatives in the mitigation of the environmental impacts of opera theatre infrastructures are those promoted by the SAIL consortium led by Opera North in Leeds [23], the Welsh National Opera [24], or the Gran Teatre del Liceu in Barcelona [25]. Amongst them all, the most iconic case is that of the Sydney Opera House which was awarded a 5 Green stars performance rating from the Green Building Council of Australia in 2015 [26] and a carbon neutral certification by the Australian Government's National Carbon Offset Standard (NCOS) in 2018 [27]. The Sydney Opera House gained this recognition after implementing a new waste management program that significantly reduced water and energy use. Moreover, these awards acknowledged its efforts to develop a global Environmental Action Plan 2020-23 aiming to cover a wider scope of activities of the opera house including opera sets [27]. Another iconic opera house, La Scala in Milan, has aimed to lead changes in the Italian cultural sector and worked to reduce carbon emissions by over 630 tons since 2010 with changes in its lighting systems, energy and materials sourcing, and waste management [12].

The environmental impacts of opera productions have until recently not received central attention. This is especially true regarding the impacts associated to on-stage sceneries. Only in the past few years have a few initiatives, amongst them the OSCaR [28], started to contemplate a general need for the scenic arts sector to move forward in reducing the associated impacts of sets. These initiatives are aiming to generate and promote guidelines to push forward sustainable practices of on-stage activities with the objective of creating common standards $[13,14,29]$. At the individual level, some opera houses have pioneered initiatives related with conducting a complete life cycle assessment (LCA) of opera sets to mitigate their impacts: Aix en Provence festival [30], and the Gotteborg's opera and the Regionteater Väst (both documented in [20]).

In addition to the abovementioned studies, Opera de Lyon developed EDEOS, an internal and simplified eco-design tool to conduct a LCA of opera sets [31]. It includes four impact categories: global warming potential, human toxicity, use of biogenic resources, and fossil fuel consumption. The tool is aimed at helping decision-making by providing the environmental footprint of alternative opera set designs.

At this point it is worth mentioning that no specific work has been performed to identify the common challenges to enhance the sustainability of opera sector sceneries whilst contemplating a life cycle (LC) perspective. This study aims to contribute to filling this gap by including this LC perspective, considering raw material sourcing, set production, use, end-of-life treatment, recycling and final disposal, and looking for information related to the amount of energy used, the materials consumed, and the treatment of the disposed waste.

\subsection{Results of the Interviews}

The interviews included three sections. Section one referred to the definition of the LC of opera sets, Section two analyzed the relevance of each of the phases to the overall environmental impact, and finally, Section three focused on more general and global relations between the sector and its environmental impacts.

\subsubsection{Definition of the LC of Opera Sets}

This section of the interview asked participants to propose a diagram of the LC of opera sets, including upstream, main, and downstream related activities. The interviewees were asked to suggest activities to be considered in the different phases of the LC of 
opera sets. We hereby provide an account of the inputs that they provided to obtain the resulting LC diagram (see Figure 2). Regarding the design phase, it was pointed out that an appropriate approach to the conceptualization of the LC of opera sets was that provided in the framework defined by the methodological guide of the Aix en Provence festival (2018). In accordance, interviewees suggested to include the assembly, the performance itself, and the disassembly of opera sets amongst the main activities of the set LC. Additionally, they suggested to differentiate disassembling from transport and logistics and to separate these from the end-of-life stage, to be considered downstream activities which could be occurring several times during the LC of an opera. The dismantling and waste management of the opera sets should, on the other hand, be part of the end of life of the opera sets.

\begin{tabular}{|c|c|c|}
\hline \multirow{3}{*}{$\begin{array}{l}\text { UPSTREAM } \\
\text { Activities }\end{array}$} & Raw material extraction & \multirow{11}{*}{ Reuse / Rent / Donation } \\
\hline & Basic product manufacturing & \\
\hline & Transport & \\
\hline \multirow{5}{*}{$\begin{array}{l}\text { MAIN } \\
\text { Activities }\end{array}$} & Sets design & \\
\hline & Sets building & \\
\hline & Sets use & \\
\hline & Sets disassembling & \\
\hline & Sets storage & \\
\hline \multirow{3}{*}{$\begin{array}{c}\text { DOWNSTREAM } \\
\text { Activities }\end{array}$} & Sets transport & \\
\hline & Sets end-of-life & \\
\hline & Waste management & \\
\hline
\end{tabular}

Figure 2. Diagram of the life cycle of opera sets.

\subsubsection{Assessment of the Environmental Impacts along the LC of Opera Sets}

Next follows an account of what the interviewees mentioned as the most significant environmental impacts along the LC of opera sets when considering the materials used, the energy consumed, and the waste generated at the different phases. Moreover, interviewees indicated what actions they envisaged to improve the impacts identified.

The decisions taken in the design phase of the LC of opera sets determine the upstream activities and, thus, their associated environmental impacts. This includes decisions regarding what materials to purchase and to use in the construction of opera sets. Interviewees described the practice of purchasing the most common materials by weight and that the supply chain and associated impacts of these materials are very infrequently considered. Correspondingly, ecolabeling is very rarely considered as a criterion for purchasing materials. This includes the supply of steel, wood, and aluminum; and, in a lesser amount, PS, PC, PVC, PMMA, PEHD, cotton fabrics, polyester fabrics and acrylic paints, which have important environmental impacts. Contrarily, high amounts of energy may be consumed, not directly due to the design process, but derived from the transportation of the materials and products used to build opera sets. Whilst the sourcing of materials was considered a very relevant environmental factor in the upstream activities, the associated waste generated in these stages was expected to be low, despite the fact that they might determine the recyclability of waste to be disposed of in the downstream phases. Interviewees suggested that actions to be taken to mitigate the environmental impacts associated with the upstream and design phases involved minimizing the quantity of materials purchased and used by standardizing structures and designing modular elements to make them easily reusable. The interviewees highlighted that the main challenges to achieving these goals were the specificity of each opera set to each performance and artistic creation, and that the available resources and artistic criteria frequently did not align with sustainability concerns. In summary, the interviewees raised the need to align sustainability goals with the existing governing criteria for decision-making in the design phase. 
Interviewees indicated that the building phase had a potentially more reduced impact than previous stages and that these were likewise determined by the design phase. Actions to foster sustainability at this stage should focus on the reduction of waste and increasing recyclability. Concerning the challenges to be tackled during this phase that might hinder the inclusion of sustainability considerations at this stage, the interviewees highlighted a scarcity of resources (time and budget) and the limited physical space available to store reusable parts and materials.

Interviewees evaluated that during assembly, disassembly, and the actual use during performances, the materials used and waste generated were not significant, while energy consumption associated with the activities performed during these phases was considered the main impact to assess and to be tackled. The implementation of more efficient technologies and considering alternative renewable sources of energy might be beneficial in this respect.

The logistics-related phases, comprising loading, transport, and storage, again were linked to energy usage. Interviewees identified that a potential improvement in this area would include promoting a wider standardization of structural elements to avoid having to transport them when sceneries tour to different opera houses.

The interviewees highlighted that the end-of-life treatment of waste differs vastly among different operas. While some organizations outsource the management of waste to a logistics company, others dispose of waste via municipal waste management systems.

\subsubsection{Global Considerations}

In the last section of the interview, respondents reiterated that the design of opera sets is the activity that more crucially determines their impacts as the decisions taken at this stage affect the entire LC.

They indicated their perception that sustainability would imply the need for an increase in the budget destined to opera sets to purchase more sustainable materials, reduce the impacts of logistics and enhance the reuse of sets.

As actions to be undertaken to enhance sustainability, interviewees highlighted the developing of standards for structural elements, developing Carbon Footprint assessment tools, and raising environmental awareness amongst opera stakeholders as important. Finally, when asked to indicate the most important challenges in enhancing the sustainability of the sector, interviewees stressed the need to change the mind-set of the sector stakeholders including artists and managers; reaching an agreement among opera houses on the shared use of standardized systems; and improving institutional support and resources (time, budget, and materials) devoted to sustainability. The interviewees suggested that a path to overcome these challenges would be to establish a set of general recommendations addressed to the different agents within opera organizations, targeting specific actions aimed at reducing GHG emissions, while preserving the necessary creativity and aesthetics associated with the artistic component of opera activities.

\subsection{Results of the Survey}

\subsubsection{Organizational Environmental Monitoring}

Out of the 24 participant organizations, 6 indicated that they had environmental accreditations: ISO 14000 (3); ISO 50000 (1), EMAS (1), and Ekokompas (2). Besides certification, the respondents indicated whether there was an active monitoring of the environmental impacts of their organizations in terms of the usage of specific materials, sources of energy consumed, and fractions of waste generated (see Table 3).

Finally, the participants were asked whether they were partnering with other organizations to enhance sustainability. Nine of the participants answered positively $37.5 \%$ of respondents). 
Table 3. Number (n) and percentage (\%) of participants collecting information regarding the use of materials, energy, and the generation of waste.

\begin{tabular}{ccc}
\hline Information & $\mathbf{n}$ & $\%$ \\
\hline Materials usage (responses =15) & 1 & $6.7 \%$ \\
Not collecting & 10 & $66.7 \%$ \\
Aggregate amount & 12 & $80.0 \%$ \\
Wood & 12 & $80.0 \%$ \\
Aluminum & 7 & $46.7 \%$ \\
Dense plastic polymers & 4 & $26.7 \%$ \\
Expanded plastic polymers & 2 & $13.3 \%$ \\
Cardboard and paper & 5 & $33.3 \%$ \\
\hline Energy usage information (responses $=14)$ & & \\
Not collecting & 1 & $7.1 \%$ \\
Aggregate amount & 12 & $85.7 \%$ \\
Electricity & 10 & $71.4 \%$ \\
Fossil fuel & 6 & $42.9 \%$ \\
\hline Waste generated information (responses $=11)$ & & \\
Not collecting & 2 & $18.2 \%$ \\
Aggregate amount & 9 & $54.8 \%$ \\
Steel & 6 & $45.5 \%$ \\
Aluminum & 5 & $63.6 \%$ \\
Wood and derivatives & 7 & $36.4 \%$ \\
Cardboard and paper & 4 & $18.2 \%$ \\
Glass & 2 & $9.1 \%$ \\
Plastic & 1 & $18.2 \%$ \\
General & 2 &
\end{tabular}

\subsubsection{Practices with Respect to Opera Sets}

To evaluate the durability and use of the opera sets, the respondents were asked to provide the average lifespan of their sets and the average number of cycles of assemblydisassembly that each set underwent in their organization. The reported average lifespan of the opera sets of participant organizations was 6.8 years $(\mathrm{SD}=3.4)$ and the average number of cycles of assembly-disassembly of each set was 10.1 cycles $(\mathrm{SD}=12.8)$.

Next, the survey asked participants to evaluate the common practices with respect to opera sets. Participants were also asked to indicate the extent to which certain criteria was relevant in their purchases of materials and structures for opera sets. Table 4 presents the different criteria evaluated and the results obtained. The criteria that were evaluated as more important were aesthetics, price, and availability.

Table 4. Mean and standard deviation (SD) of the importance that the organization of participants gives to each purchasing criteria, from 1 'not important' to 7 'very important'.

\begin{tabular}{ccc}
\hline Total Responses $=\mathbf{2 3}$ & Mean & SD \\
\hline Aesthetics & 6.0 & 1.2 \\
Price & 5.6 & 1.4 \\
Availability & 5.3 & 1.7 \\
Partnerships with suppliers & 5.0 & 1.7 \\
Durability & 5.0 & 1.6 \\
Geographical proximity & 4.8 & 1.9 \\
Ecolabel & 4.4 & 1.9 \\
Renewable materials & 3.9 & 1.8 \\
\hline
\end{tabular}

The survey asked participants to indicate whether their organizations were implementing certain processes and considering sustainability determinants in the life cycle of their opera sets. This included considerations regarding the materials and the structures used as well as the degree of standardization and compatibility of these for their use in different 
venues and organizations. Table 5 depicts the extent to which participant organizations applied the described practices.

Table 5. Mean and standard deviation (SD) of the extent to which organizations applied certain environmental practices when building opera sets, evaluated from 1 'not at all' to 7 'always/completely'.

\begin{tabular}{ccc}
\hline Total Responses = 24 & Mean & SD \\
\hline Materials & & \\
Ask wood suppliers for documents on the origin of their products & 4.2 & 2.8 \\
Use water-based paints & 6.2 & 0.9 \\
Reuse materials or parts of old sets & 3.8 & 1.8 \\
Adapt the dimensions of sets to fit material standards & 4.4 & 1.8 \\
Look for substitutes to polystyrene & 4.4 & 2.0 \\
Look for substitutes to other non-recyclable materials & 4.2 & 1.8 \\
Structures & & \\
Use modular parts that can then be reused & 4.7 & 1.7 \\
Rent structures to avoid construction & 2.2 & 1.3 \\
Use permanent assemblies: gluing, welding, or other methods & 5.0 & 1.6 \\
Use reversible assemblies/dismountable parts & 4.3 & 1.5 \\
Use single-material parts to facilitate their waste management & 3.4 & \\
\hline Degree of standardization and compatibility & & 2.0 \\
Standardization of mechanical systems (revolves, elevators, rakes) & 4.8 & 1.9 \\
Standardization of access structures (stairs, railings, walkways) & 4.1 \\
Standardization of horizontal structures & 3.7 & 2.0 \\
Standardization of vertical structures & 3.4 & 1.7 \\
Compatibility of structures with other operas & 3.5 & 1.7 \\
\hline
\end{tabular}

Out of the practices evaluated, the most frequent sustainability related material used was water-based paints (6.2), whereas the reuse of materials from parts of old sets was indicated to be the most uncommon practice (3.8). Regarding structures, participants indicated that the most frequent practice was using permanent assemblies (5.0) rather than modular, reversible, or dismountable parts for later use. Renting structures was indicated to be quite infrequent (2.2). Finally, whereas standardization and compatibility were indicated to be high for mechanical systems (4.8), vertical structures obtained the lowest average evaluation for compatibility (3.4).

Participants evaluated the contribution that the different activities along the LC stages of opera sets had in their environmental impacts and the scope they had to reduce these impacts at each stage in their organizations. The construction stage was the phase with both a higher average impact contribution and a higher scope for impact reduction. Table 6 presents the mean of the share of environmental impact contribution that participants answered they considered that each phase had, as well as the scope for impact reduction in these stages.

Table 6. Mean and standard deviation (SD) of contribution to the environmental impacts of opera sets and of the scope for impact reduction for the different phases of the life cycle of opera sets, evaluated from 1 'no room for improvement' to 7 'large room for improvement'.

\begin{tabular}{ccccc}
\hline Total Responses = 24 & \multicolumn{2}{c}{ Impact Contribution } & \multicolumn{2}{c}{ Scope for Reduction } \\
Mean & SD & Mean & SD \\
\hline Construction: materials and basic products & $34.2 \%$ & 14.1 & 4.7 & 1.7 \\
Use during performances and rehearsals & $16.7 \%$ & 14.3 & 3.7 & 1.9 \\
Assembling, disassembling and storage & $16.2 \%$ & 13.0 & 3.2 & 1.7 \\
Transport of sets to store, reuse, or waste them & $20.4 \%$ & 12.1 & 4.5 & 2.0 \\
Waste management & $18.8 \%$ & 10.7 & 4.3 & 1.9 \\
\hline
\end{tabular}

Participants were also asked to identify the final destinations of the materials of opera sets that were not reused for their own productions, sold, or donated. Out of 
the 24 participants, a majority indicated to be recycling materials (91.7\%); however, an important amount also acknowledged the practice of waste landfilling (45.8\%) and incineration $(25.0 \%)$.

\subsubsection{Challenges toward Sustainability}

Participants were asked to provide whether certain factors were preventing more sustainable practices at their organization. Money was the factor that obtained the most affirmative answers (58.3\%), followed by time (50.0\%), work habits (45.8\%), knowledge of alternatives $(41.7 \%)$, and manpower $(29.2 \%)$.

A classification of the open-ended request to provide an account of the main challenges to achieving an enhanced sustainability of the practices in the opera sector, shows that the majority of participants identified challenges related with the particularities of the design, materials, and structures required to construct the sets (13 participants, 54.2\% of the respondents), followed by the resources available, including time and money (8 participants, 33.3\% of the respondents), the degree of awareness, involvement, and training of professionals (7 participants, $29.2 \%$ of the respondents), and the existence of associated legal requirements (4 participants, $16.7 \%$ ).

\subsection{Results of the Experts' Forum}

Table 7 presents the classification of comments resulting from the content analysis. It depicts the number and percentage of comments in each of the five classification categories. The transcription of the insights received, and their classification is provided as Supplementary material (S3).

Table 7. Number of contributions in each of the classification categories.

\begin{tabular}{|c|c|c|c|}
\hline & Category & Count & $\%$ \\
\hline \multirow{4}{*}{ Organization } & Resources & 7 & $14 \%$ \\
\hline & Knowledge & 11 & $22 \%$ \\
\hline & Criteria & 12 & $24 \%$ \\
\hline & Management & 7 & $14 \%$ \\
\hline \multicolumn{2}{|c|}{ Sector } & 8 & $16 \%$ \\
\hline \multicolumn{2}{|c|}{ External } & 5 & $10 \%$ \\
\hline
\end{tabular}

The categories into which more insights were classified were Knowledge $(22 \%$ of the pieces of information), stressing the need for capacitation, awareness, and substantiating data to put sustainability initiatives into practice; and Criteria ( $24 \%$ of the pieces of information) indicating the role of the hierarchy of priorities, interests, and values in facilitating or hindering these initiatives.

Comments related with Resources (14\%) referred to the need of available production and planning time to take informed decisions, the need for space to store sets, the need for labor and training to deal with the structures and sets appropriately and the need for financial resources.

Comments related with Knowledge (22\%) referred to the need for training, deep reflection, and awareness regarding sustainability issues as well as the lack of detailed information. The need for awareness in turn is expressed to have, to cover from the managerial to the artistic crew as well as to the technical and the production departments. The need for detailed information should include information about the sourcing of materials, the potential impacts of the LC of sets and the alternatives available to achieve comparable aesthetic results.

The Criteria category ( $24 \%$ ) collects the different interests and priorities that need to be balanced in the decisions taken in the LC of opera sets. The different contributions include the following criteria: aesthetics, artistic freedom, artistic quality, functionality, transportability, local sourcing, affordability, sustainability, waste generation, and environmental image gained by the organization. 
Management (14\%) is related to the need for commitment towards sustainability to be incorporated in the organization's decision-making processes. This category has several communalities with that of Criteria and Resources, as the priorities of the organization and the distribution of the resources available are usually fixed by the organization's management. Insights in this category stress the need for opera organizations to weigh and manage different priorities and combine everyday decisions with a more strategic vision, which requires a full engagement from all the stakeholders to set the objective to become more environmentally sustainable.

Insights at a Sector level $(16 \%)$ describe the desirability as well as the difficulty to produce a change that involves all organizations in the opera industry by the time it becomes legally required to have reduced its environmental impacts. The discussion stresses the sector does not yet have sufficiently established standards that guide the pursuit of environmental practices in the domain of opera sets, and it is thus necessary to engage in a sectoral analysis to organize actions and set exemplary models to be followed by individual organizations and collaborative productions.

Finally, the External factors $(10 \%)$ mentioned as relevant to the development of more sustainable practices included the pressure exerted by the young audiences and the public as well as political demands and legal responsibility, particularly pressing in times of the COVID-19 pandemic and the climate change crisis.

\section{Discussion}

To synthesize our research and integrate the insights gained with the literature review and the results of our primary research, we discuss the internal and external factors conditioning the environmental impacts and sustainability of the opera organizations and sector in the form of a Strengths, Weaknesses, Opportunities, and Threats (SWOT) analysis. As in previous social and environmental studies (e.g., [32,33]), the SWOT analysis aims at identifying the inherent factors of the sector that constitute an advantage (strengths) or disadvantage (weaknesses) towards the goals set, in our case, the environmental sustainability of opera sets, and the external elements that may facilitate (opportunities) or hinder (threats) their achievement.

\subsection{Internal Analysis (Strengths and Weaknesses)}

Creativity and innovation are at the heart of artistic creation, which is in turn a central purpose of opera houses. Whereas aesthetics and artistic criteria have been found to usually prevail over sustainability concerns in the decision-making processes of opera houses, the creativity and innovative forces within the organization are a powerful transformative asset to achieve environmental goals. This fact, paired with an increased sensitivity regarding sustainability concerns within opera organizations, as exemplified with the growing number of related initiatives, shall play an important role in promoting a shift towards more sustainable practices. Moreover, the fact that a mission of opera houses is to disseminate culture should further enhance a willingness to incorporate and share sustainability values and concerns to engage the audience with the challenges that they pose.

The interviews and experts' forum we performed, allowed for identifying further inner characteristics of the sector that could become fundamental in its path towards sustainability. First is the fact that opera house managers are already accustomed to balancing different criteria, requirements, and concerns. The constraints and considerations to be managed in the different stages of the LC of opera sets include those related with aesthetics, the time available, budgetary constraints, the dimensions of the theatre, security measures, etc., which may frequently imply opposite criteria. Sustainability adds complexity to the decision-making processes but, at the same time, it may turn out to be a conflictresolving determinant that may be introduced in the working conditions of suppliers and subcontractors, designers, production, and post-production services.

A related trait of the sector is the fact that there exist already tight collaborations across organizations. These well-established relations could act as channels to standardize 
and disseminate protocols for its transformation to achieve environmental goals. These collaborations include, on the one hand, the close relation that opera houses have with their suppliers, subcontracted workshops, artists, technical professionals, public and private cultural institutions, etc. On the other hand, different opera theatres frequently collaborate to develop joint productions and venues. Moreover, the opera sector counts with multiple associations, such as Opera Europe, Opera America, Opera for Peace, Fedora, or RESEO, amongst others, which have the aim to promote collaboration and innovative practices. This intense collaborative framework constitutes an ideal starting point to push forward the sector towards setting sustainability targets. These common goals could emerge from sustainability pioneering pilot experiences aiming to set standards for the sector.

Several aspects of the opera sector and their organizations were outlined as inherent weaknesses to be overcome in their path towards sustainability. At an organizational level, the results of the interviews, the survey, and the experts' forum similarly pointed out that there is a lack of involvement and alignment of the different levels of the organizations with regards to sustainability objectives. This relates with, on the one hand, the existence of other predominant criteria and, on the other, with a scarcity of information regarding the impacts and potential alternatives of action that the decision-makers should take into consideration. When taking decisions, economic and artistic criteria generally take precedence at the managerial level and are frequently perceived as being opposed to sustainability criteria. This poses an important barrier for technical departments to incorporate sustainability considerations into their decisions regarding the materials and technical solutions incorporated in the productions.

Moreover, the temporary and ephemeral nature of a good number of opera venues and the specificity of requirements that artistic creations impose on the characteristics of sets, as well as the intellectual property rights of productions may substantially reduce the possibilities for organizations to consider standardizing structures and making them compatible for different performances. Their standardization would enable the reuse of sets to reduce the associated environmental impacts.

The survey performed, and later corroborated in the discussion forum, found that opera organizations do not systematically collect detailed information regarding the use of materials, energy, and the generation of waste. Obtaining such information would be fundamental to developing a strategy to enhance organizational and sectorial sustainability. There is an urgent need to assess the impacts and reconsider the type and quantity of materials used. A common perception amongst technical professionals is that reused, recycled, modular, and reusable components that facilitate assembly and disassembly and extend the lifespan of materials have not been sufficiently prioritized. Similarly, attention should be placed on minimizing the use of new virgin materials from unsustainable distant sources requiring significant transport. Sets and scenery mainly use steel, softwood, laminated materials, and plastics which have considerable environmental footprints. The most damaging materials given their scarcity, manufacture, or chemical harm are identified to be polystyrene, $\mathrm{PVC}$, unrecycled steel, and tropical hardwoods. As stressed in the experts' forum, requiring suppliers' information and evaluating the footprint of the materials used and their storage management is quintessential to evaluating the alternatives of action. Also, making shows sustainably would require reducing transport and deliveries and prioritizing those with lower emissions, promoting networks and sharing systems to boost reuse initiatives. Achieving sustainability implies considering sustainability since from the outset it involves planning, design, and managing of the production, developing collective responsibility and teamwork, collecting and communicating data on the use of resources, and facilitating tools and information (such as material passports, material inventories, or carbon calculators) and training.

\subsection{External Analysis (Opportunities and Threats)}

The opera sector is part of the cultural and arts industry which is experiencing dramatic changes, especially due to two external factors: the advancement of digitalization and technical 
solutions and the irruption of the COVID-19 pandemic. Both pose important opportunities and threats with respect to the challenges of pursuing more sustainable productions.

The sweeping changes brought about by the digital and technological revolution have had a dramatic effect on the cultural and arts industry. On the one hand, technical innovations have transformed opera design and production, in many instances reducing the use of energy and materials, enabling the use of alternative sources of energy, and reducing the generation of waste; however, as our research shows, a predominant criterion of the opera sector is that of the aesthetic excellence of artistic creations, which has often prevented even more radical changes to achieving environmental sustainability. The digital revolution experienced is also linked with changes in the lifestyle, preferences, and behavior of consumers of the arts and cultural sector. The emergence of alternative forms of recreational activities, the improved quality of home sound and image systems, and the perception that "classic" forms of culture such as opera and ballet may be outdated and elitist, pose an important threat to the sector. Thus, opera organizations may consider engaging in actions to widen its audience to align with the changing values of society. Embracing sustainability concerns at the corporate level as well as in their designs and even as a theme for new creations, such as that which the association Opera for Peace is promoting, could represent an opportunity to achieve this goal whilst improving the public image of opera organizations. The existing parallelism between artistic values and the concepts of a circular economy and sustainability in aiming to boost human progress could foster the possibility for creating new paradigms within the sector and for generating new opportunities for opera artists.

The COVID-19 pandemic has put the cultural industry in the spotlight due to the need to limit the audience capacity of public performances, which has implied an important economic tension for the organizations and professionals involved. As much as the reduction of resources and the need to ensure sanitary conditions has potentially diverted the attention of opera house managers from sustainability concerns and in some instances increased environmental impacts, the need for a change of paradigm and the implementation of new practices have shaken organizations. This turmoil may represent an opportunity to push forward structural reforms. Aligning the mechanisms and requirements of public recovery funds that the cultural sector is bound to receive with sustainable goals can act as an important trigger in this respect. The increasing awareness and concern of public bodies and administrations with the need to reduce environmental impacts shall play a substantial role in pushing the opera sector towards enhanced sustainability practices.

Table 8 presents a summary matrix of the SWOT analysis. The internal strengths and weaknesses encountered align with the need for the opera sector to accommodate new parameters and constraints in the design processes of opera set productions additional to the traditional governing criteria. The perception of rivalry between economic, artistic, and sustainability criteria ought to be reassessed. Its analysis should test whether the incorporation of certain sustainability practices hinders artistic quality standards, freedom of authorship, and creativity, as well as the economic results of productions. This research should ultimately aim to contribute to developing new practices to prevent these potentially detrimental interlinked effects. Aligned with this, as was mentioned in the experts' forum, it becomes paramount that sustainability is sponsored from the top managerial levels and integrated in the organizational culture. Sustainability management, impact assessment, and reporting should emerge as a function within the organizations to involve, capacitate, and empower the different stakeholders (producers, directors and designers, production managers, production staff, makers, and communication and PR units), and to generate a common operationalization of sustainability by developing toolkits, handbooks, guidelines (including materials' passports and inventories) and disposal protocols to push forward progressive actions towards environmental objectives. 
Table 8. SWOT analysis matrix.

\begin{tabular}{|c|c|c|}
\hline & Positive & Negative \\
\hline Internal & $\begin{array}{l}\text { Strengths: } \\
-\quad \text { Creativity and innovation. } \\
-\quad \text { Growing sensitivity toward } \\
\text { sustainability concerns. } \\
-\quad \text { Already balancing different } \\
\text { criteria, requirements, and } \\
\text { concerns. } \\
-\quad \text { Existing cross-organizational } \\
\text { collaborations and associations. }\end{array}$ & 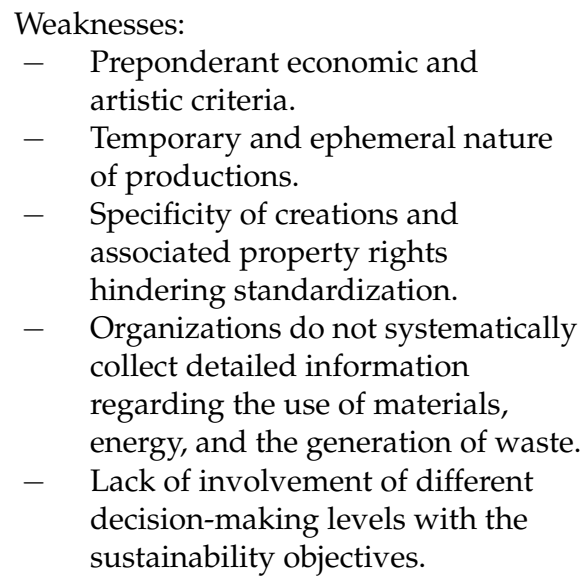 \\
\hline External & $\begin{array}{l}\text { Opportunities: } \\
-\quad \text { Aligning the organization and } \\
\text { creations with the values of the } \\
\text { public linked } \\
\text { with sustainability. } \\
-\quad \text { Technological advancements } \\
\text { reducing the impacts of opera } \\
\text { sets: energy use, sourcing, and } \\
\text { waste generation. } \\
-\quad \text { Public recovery } \\
\text { funds incorporating } \\
\text { sustainability standards. }\end{array}$ & $\begin{array}{l}\text { Threats: } \\
\text { - Changes in consumer preferences } \\
\text { threatening the economic } \\
\text { sustainability of the sector. } \\
-\quad \text { Potential increase of impacts due to } \\
\text { the sanitary regulations of the } \\
\text { COVID-19 pandemic. } \\
\text { - Economic difficulties due to the } \\
\text { COVID-19 pandemic. }\end{array}$ \\
\hline
\end{tabular}

\section{Conclusions}

The opera is a traditional cultural sector, where artistic creation and aesthetic parameters are central. The enrooted practices of its organizations pose an important challenge to the need to place sustainability as one of the main goals to be achieved in the coming years; however, as the demands of society to move towards more sustainable practices grow, opera organizations are becoming more aware of the need to use its creative and innovative capacity to incorporate new standards linked with sustainability, and to perform an exemplary role for the cultural and scenic arts. Thus, embracing sustainability should be promoted as a channel of creativity and invention to improve the efficiency and artistic results of the processes involved in the production of operas whilst contributing to boost their public image, by raising public awareness of sustainability concerns and serving as a role model for other sectors.

This study constitutes a novel effort to bring together the state-of-the art existing practices and initiatives and to gather qualitative and quantitative insights from experts in the field to identify the main challenges that the opera sector faces in the pursuit of sustainability. This unprecedented attempt to assess the main areas in need of amelioration places a particular focus on the life cycle of opera sets, a domain that has typically been omitted from the improved practices of the sector and which entails an important potential for impact mitigation.

To boost the introduction of sustainability practices into the sector, it is critical to raise awareness amongst the artistic, technical, production, and management departments of opera organizations as well as that of public authorities. The identification of the strengths, weaknesses, opportunities, and threats of the sustainability of the sector with which our research contributes, should ultimately serve to push forward the rethinking of existing practices. This should be undertaken by reconsidering the entire life cycle of opera sets, from their design to their end-of-life, with the cooperation between all potential 
stakeholders, and with the goal to ultimately establish a Sectoral Sustainability Roadmap including a specific action plan to achieve environmental goals. This Roadmap should comprise a completely renewed mindset, revolutionizing the principles and practices of the sector, and pioneering the dramatic change that the scenery arts industry must embrace to achieve sustainability by aligning its practices with the SDGs.

Supplementary Materials: The following are available online at https:/ /www.mdpi.com/article/10 $.3390 /$ su132212896/s1, S1: protocol of structured interviews, S2: survey questionnaire, S3: classification of discussion forum insights.

Author Contributions: Conceptualization, M.R., J.A., A.B., L.B.-B., J.R.-T. and P.F.-i.-P.; data curation, M.R.; formal analysis, M.R.; funding acquisition, A.B. and P.F.-i.-P.; investigation, M.R., J.A., A.B. and L.B.-B.; methodology, M.R., J.A. and A.B.; project administration, A.B. and P.F.-i.-P.; resources, A.B. and P.F.-i.-P.; supervision, A.B. and P.F.-i.-P.; validation, M.R., J.A., A.B., L.B.-B., J.R.-T. and P.F.-i.-P.; writing—original draft, M.R.; writing—review and editing, M.R., J.A., A.B., L.B.-B., J.R.-T. and P.F.-i.-P. All authors have read and agreed to the published version of the manuscript.

Funding: This work has been completed under the OSCaR project which was co-funded by the Creative Europe Programme of the European Union (607536-CREA-1-2019-1-FR-CULT-COOP1).

Institutional Review Board Statement: Not applicable. The study does not involve human/animal experimentation.

Informed Consent Statement: Informed consent was obtained from all subjects involved in the study.

Data Availability Statement: The data used are presented in the main manuscript, further details are available on request from the corresponding author. The protocols used to collect the data are included as Supplementary Materials.

Acknowledgments: The authors would like to thank the collaboration of Opera Europa and the participants in the interviews, the survey, and the experts' forum panel for their contributions to the research. The authors are responsible for the choice and presentation of the information contained in this paper as well as for the opinions expressed therein, which are not necessarily those of UNESCO and do not commit this Organization.

Conflicts of Interest: The authors declare no conflict of interest.

\section{References}

1. UN. UN General Assembly Resolution on the 2030 Agenda and the Sustainable Development Goals. General Assembly Seventieth Session; Agenda Items 15 and 116. A/RES/70/1 of 25 September 2015. Available online: https://www.un.org/ga/search/view_ doc.asp?symbol=A/RES/70/1\&Lang=E (accessed on 6 September 2021).

2. UNFCCC. Paris Agreement, 21st Conference of the Parties. Doc Number: FCCC/CP/2015/L.9/Rev1. 2015. Available online: https://unfccc.int/resource/docs/2015/cop21/eng/109r01.pdf (accessed on 6 September 2021).

3. EC. Communication from the Commission to the European Parliament, the European Council, the Council, the European Economic and Social Committee and the Committee of the Regions. The European Green Deal. 2019. Available online: https: / / eur-lex.europa.eu/legal-content/EN/TXT/?qid=1576150542719\&uri=COM\%3A2019\%3A640\%3AFIN (accessed on 6 September 2021).

4. EC. Communication from the Commission to the European Parliament, the Council, the European Economic and Social Committee and the Committee of the Regions. A new Circular Economy Action Plan for a cleaner and more competitive Europe. 2020. Available online: https:/ / eur-lex.europa.eu/legal-content/EN/TXT/?qid=1583933814386\&uri=COM:2020:98:FIN (accessed on 6 September 2021).

5. WBCSD. SDG Sector Roadmap Guidelines. How to Leverage the Power of Sectoral Collaboration to Maximize Business Impact on the Sustainable Development Goals. 2018. Available online: https:/ /www.wbcsd.org/contentwbc/download/4904/64836/1 (accessed on 6 September 2021).

6. UCLG. Culture: Fourth Pillar of Sustainable Development. 2010. Available online: https:/ /www.agenda21culture.net/sites/ default/files/files/documents/en/zz_culture4pillarsd_eng.pdf (accessed on 6 September 2021).

7. Pop, I.L.; Borza, A.; Buiga, A.; Ighian, D.; Toader, R. Achieving Cultural Sustainability in Museums: A Step Toward Sustainable Development. Sustainability 2019, 11, 970. [CrossRef]

8. Greenfield, B. Review: Environmental Sustainability at Historic Sites and Museums by Sarah Sutton. Public Hist. 2017, 39, $153-154$. [CrossRef]

9. Petti, L.; Trillo, C.; Makore, B.N. Cultural Heritage and Sustainable Development Targets: A Possible Harmonisation? Insights from the European Perspective. Sustainability 2020, 12, 926. [CrossRef] 
10. Lopera-Mármol, M.; Jiménez-Morales, M. Green Shooting: Media Sustainability, A New Trend. Sustainability 2021, $13,3001$. [CrossRef]

11. Collins, A.; Cooper, C. Measuring and managing the environmental impact of festivals: The contribution of the Ecological Footprint. J. Sustain. Tour. 2017, 25, 148-162. [CrossRef]

12. Schmid, R. How Operas are Going Green. The New York Times. 10 May 2021. Section A, p.10 of the International Edition. Available online: https:/ / www.nytimes.com/2021/05/10/arts/music/opera-sustainability.html (accessed on 6 September 2021).

13. Bicycle, J. How to Limit Environmental Impacts at Every Stage in the Production Process. Sustainable Production Guide. 2013. Available online: https://juliesbicycle.com/wp-content/uploads/2019/11/Sustainable_Production_Guide_2013.pdf (accessed on 6 September 2021).

14. Buro Happold. The Theatre Greenbook 1: Sustainable Productions (Version Beta.2 for Trialling). 2021. Available online: https://theatregreenbook.com/wp-content/uploads/2021/03/THEATRE-GREEN-BOOK-ONE_beta1.pdf (accessed on 6 September 2021).

15. Fedora. Next Stage. 2021. Available online: https://www.Fedora-Platform.Com/Discover/News/Introducing-next-Stage-anInitiative-for-Change-and-Recovery / 187 (accessed on 6 September 2021).

16. Albertí, J.; Balaguera, A.; Brodhag, C.; Fullana-I-Palmer, P. Towards life cycle sustainability assessment of cities. A review of background knowledge. Sci. Total. Environ. 2017, 609, 1049-1063. [CrossRef] [PubMed]

17. Neuendorf, K.A. The Content Analysis Guidebook; SAGE Publications, Inc.: Thousand Oaks, CA, USA, 2017. [CrossRef]

18. Feeny, A. The Financial Sustainability of Opera and Orchestral Music. Ph.D. Thesis, Royal Holloway, University of London, London, UK, 2018.

19. Tajtakova, M. Flexibility of strategic choices in an opera house management. Int. J. Bus. Environ. 2006, 1, 365. [CrossRef]

20. Tengström, J.; Izurieta, F. LCA of Stage Performances. Master's Thesis, Department of Energy and the Environment, Chalmers University of Technology, Göteborg, Sweden, 2010. Available online: https:/ / odr.chalmers.se/bitstream/20.500.12380/141433/1/ 141433.pdf (accessed on 6 September 2021).

21. Opera for Peace. Opera for Peace Announces New Initiative with OCCE. 2021. Available online: https://Operaforpeace.Org/ News/Opera-for-Peace-Announces-New-Initiative-with-the-Occe/ (accessed on 6 September 2021).

22. Groen, M. Transparency in Environmental Policy of Theatres: A Comparison of British and Dutch Theatres. Master's Thesis, Radboud University, Nijmegen, The Netherlands, 2020.

23. Opera North. Sustainability: Our Environmental Aims. 2021. Available online: https://www.Operanorth.Co.Uk/about-Us/ Sustainability / (accessed on 6 September 2021).

24. Opera Vision. Welsh National Opera. Cooperation Projects. 2017. Available online: http://www.creativeeuropeuk.eu/fundedprojects / opera-vision-0 (accessed on 6 September 2021).

25. Liceu. Environmental and Energy Policy. 2018. Available online: https://www.liceubarcelona.cat/sites/default/files/ compromis_ambiental/1810_politica_ambiental_i_energetica_de_la_fgtl_english.pdf (accessed on 6 September 2021).

26. GBCA. Case Studies. Building Operations: Sydney Opera House. Green Building Council of Australia. 2021. Available online: https://new.gbca.org.au/case-studies/building-operations/sydney-opera-house/ (accessed on 6 September 2021).

27. Sydney Opera House. Our House is Now Carbon Neutral. Here's What it Means \& How We Made a Modern Wonder Sustainable. 2018. Available online: https://www.sydneyoperahouse.com/carbonneutral (accessed on 6 September 2021).

28. Creative Europe. Oscar, a Project for Opera Sceneries Circularity and Resource Efficiency. 2019. Available online: https://Ec. Europa.Eu/Programmes/Creative-Europe/Projects/Ce-Project-Details/\#project/607536-CREA-1-2019-1-FR-CULT-COOP1 (accessed on 6 September 2021).

29. Aix en Provence Festival. Guideline to Opera Set Environmental Approach. 2018. Available online: https:// festival-aix.com/ sites/default/files/imce/documents/ecoconception_au_festival_daix_-_le_guide_methodologique_nov_2018.pdf (accessed on 6 September 2021).

30. Aix en Provence Festival. Approach to Sustainable Development. 2019. Available online: https://festival-aix.com/en/festivaldaix/our-approach-societal-and-sustainable-development (accessed on 6 September 2021).

31. Beer, T. Opera Production \& the Circular Economy: Interview with Thierry Leonardi (Lyon Opera). Ecoscenography. 2020. Available online: https:/ / ecoscenography.com/2020/11/24/opera-production-the-circular-economy-interview-with-thierryleonardi-lyon-opera/ (accessed on 6 September 2021).

32. Christodoulou, A.; Cullinane, K. Identifying the Main Opportunities and Challenges from the Implementation of a Port Energy Management System: A SWOT/PESTLE Analysis. Sustainability 2019, 11, 6046. [CrossRef]

33. Falcone, P.M.; Tani, A.; Tartiu, V.; Imbriani, C. Towards a sustainable forest-based bioeconomy in Italy: Findings from a SWOT analysis. For. Policy Econ. 2020, 110, 101910. [CrossRef] 